\title{
Free Tissue Transfer Optimizes Stump Length and Functionality Following High-Energy Trauma
}

\author{
Merisa L. Piper, MD $\quad$ Dominic Amara, BA ${ }^{1} \quad$ Sarosh N. Zafar, MD ${ }^{1} \quad$ Charles Lee, MD ${ }^{1} \quad$ Hani Sbitany, MD \\ Scott L. Hansen, MD ${ }^{1}$ \\ ${ }^{1}$ Division of Plastic and Reconstructive Surgery, Department of \\ Surgery, University of California, San Francisco, San Francisco, \\ California

\begin{abstract}
Address for correspondence Scott L. Hansen, MD, Division of Plastic and Reconstructive Surgery, Department of Surgery, University of California, San Francisco, 505 Parnassus Avenue, Suite M-593, San Francisco, CA 94143 (e-mail: scott.hansen@ucsf.edu).
\end{abstract}

J Reconstr Microsurg Open 2019;4:e96-e101.

\begin{abstract}
Background Advances in medicine and surgery have allowed patients, who in the past would have required more aggressive amputations, to maintain longer stump lengths. Microvascular free tissue transfer has become increasingly popular to preserve limb length and optimize functionality. We present our experience using microvascular free flap reconstruction to preserve lower extremity limb length in the setting of highenergy trauma.

Methods We conducted an Institutional Review Board-approved retrospective review of patients at three San Francisco hospitals who underwent free flap reconstruction after high-energy trauma between 2003 and 2015. We included all patients who underwent free flap reconstruction for lower extremity limb length preservation. We reviewed patient demographics, preoperative variables, intraoperative details, and postoperative outcomes, including complications, functional status, reoperation rates, and need for revision amputation.

Results Twelve patients underwent microvascular free tissue transfer for limb length preservation. Overall, the patients had similar preoperative comorbidities and a mean age of 44 . Six patients had postoperative complications: three minor complications and three major complications. Seven patients had additional surgeries to improve the contour of the flap. One patient required revision amputation, while the remaining 11

Keywords

- limb salvage

- limb length preservation

- extremity reconstruction patients preserved their original limb length. The majority of patients were fully ambulatory, and four used a prosthesis.

Conclusion Microvascular free tissue transfer can be used to effectively maintain lower extremity stump length following trauma. Although these patients often require multiple surgeries and face lengthy hospital courses, this technique enables preservation of a functional extremity that would otherwise require a more proximal amputation.
\end{abstract}

Medical and surgical advances have allowed many patients who would have previously undergone amputation following trauma to undergo limb salvage instead. In the emergency setting especially, microsurgical free flaps have been increasingly used to preserve injured limbs. ${ }^{1,2}$ Despite the increased use of free flaps for limb preservation, studies on limb preser-

received

June 8, 2018

accepted after revision

October 16, 2018
DOI https://doi.org/

10.1055/s-0039-3399573.

ISSN 2377-0813. vation in the emergency setting are far from definitive. While some studies suggest that the limb preservation approach as a whole allows for an improved aesthetic result, ${ }^{3}$ other investigators have suggested that limb reconstruction often only results in an equivalent or poorer functional outcome than amputation paired with a well-chosen prosthesis. ${ }^{4-6}$ However,
Copyright $\odot 2019$ by Thieme Medical

Publishers, Inc., 333 Seventh Avenue, New York, NY 10001, USA. Tel: +1(212) 584-4662.
License terms

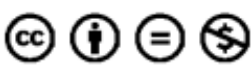


there is little data available which evaluates the aesthetic and functional outcomes of free flap coverage to preserve limb length.

In some cases, a combination of limb salvage techniques and amputation is used to preserve limb length and to optimize the functionality of the lower extremity. In these cases, free flaps are used to maintain blood flow to a portion of the extremity, allowing a more distal amputation. Longer residual limbs are known to place less physiological strain on patients than shorter residual limbs. In particular, longer preserved limbs have been correlated with lower energy expenditure in using the limb. ${ }^{7,8}$ More distal amputations have also been associated with a better prognosis for the future use of a prosthesis and for a faster return to physical activity. ${ }^{9}$

Despite surgical efforts, complex major lower-limb trauma still often results in marked disability and considerable psychological distress. $^{6,10}$ The patients examined in this study are particularly complex, given many have significant concomitant injuries in addition to mangled lower extremities resulting from high-energy trauma. We present our experience with limb length preservation using microvascular free tissue transfer in the trauma setting. We sought to evaluate the postoperative complications and outcomes, as well as the long-term functional outcomes of limb salvage in patients with devastating injuries to the extremities.

\section{Methods}

We identified 12 patients who sustained high-energy trauma resulting in mangled or otherwise nonfunctional lower extremities. These patients were treated at any one of three hospitals in San Francisco (University of California, San Francisco; San Francisco General Hospital; St. Mary's Medical Center) between 2003 and 2015. All underwent microvascular free tissue transfer to reconstruct the amputated or nonfunctional extremity to preserve limb length. The decision to pursue free flap reconstruction was made in conjunction with orthopedic surgery based on a set of clinical criteria that involved preserving limb length and the associated joint for improved functionality, abrogating the need for reamputation at a higher level, restoring the soft tissue cushion, and compensating for potential loss of sensation. Flap choice was decided on a case-by-case basis, with a preference given to muscle flaps given their reliable and robust blood supply, and their ability to contour around irregular stumps.

Charts were retrospectively reviewed for patient demographics, mechanism of injury, amputation level, indication and type of free tissue transfer, operative details, and postoperative outcomes. Outcomes assessed included complications, functional status, reoperation rates, and need for revision amputation. Complications were divided into either minor or major complications. Minor complications included infection treated with oral or intravenous antibiotics, partial skin graft loss treated with local wound care, and wound dehiscence treated with local wound care. Major complications included graft loss necessitating reoperation, wound breakdown requiring reoperation, and pulmonary embolus necessitating anticoagulation. Functional status was assessed by evaluating ambulatory status, prosthesis use, and presence of chronic pain.

\section{Results}

Two women and 10 men underwent microvascular free tissue transfer to maintain lower limb length ( Table $\mathbf{1}$ ). The mean age was 44 (range: 24-69 years). Overall the patients were healthy. Four patients were smokers, one had hypertension, one had coronary artery disease, and one had diabetes. No patients had peripheral vascular disease. However, many patients had concomitant injuries which complicated their hospital course and lengthened their hospital stay. Mean follow-up was 32.7 months (range: 2-111 months).

The injuries included five patients with significant soft tissue loss to the foot, two trans-metatarsal amputations, one Lisfranc amputation, one case of significant bone and soft tissue loss over the tibia, one below-the-knee amputation (BKA), and two through-knee amputations. Mechanisms of injury included five crush injuries, two motorcycle accidents, two pedestrian versus automobile accidents, one industrial paper shredder accident, one fall, and one motor vehicle accident.

Free flaps used for lower extremity reconstruction included five rectus abdominis muscle flaps ( - Fig. 1), five anterolateral thigh fasciocutaneous flaps, and two latissimus dorsi muscle flaps (-Fig. 2) (-Table 2). Flap choice depended on patient's body habitus, size of defect, concomitant injuries, and surgeon preference. The mean time to free flap reconstruction from date of injury was 41 weeks (range: 6 days-156 weeks). Eight patients had free flaps within 2 months of the initial injury, while the remaining patients had delayed reconstruction ranging from 8 months to almost 3 years after initial injury. Eight patients had additional operations after undergoing reconstruction, and the majority of these patients had two or more reoperations.

Six patients had postoperative complications: three patients had minor complications and three patients had major complications (-Table 3 ). The minor complications included infection treated with antibiotics, partial loss of a split-thickness skin graft (STSG), and wound dehiscence treated with local wound care. The three patients with major complications included one who had complete loss of a STSG requiring repeat STSG; one who developed wound dehiscence requiring reoperation and flap rotation, pulmonary embolus requiring anticoagulation, and a sinus tract requiring excision; and one who required reoperation for wound breakdown of the weightbearing portion of the flap. Eight patients underwent flap revision, most often for thinning of the flap to improve the contour for fitting a prosthesis or wearing a shoe. Two patients underwent a second free flap for chronic ulcerations on the plantar weight-bearing surface of the foot. Both of these patients were reconstructed with a fasciocutaneous anterolateral thigh free flap for their second reconstruction.

We found that the majority of patients were fully ambulatory and had no functional impairments. Four patients used a prosthesis postoperatively: one Lisfranc level, one BKA level, one at the level of the knee, and one for a patient who had bilateral above-knee amputations (AKAs). Less than 
Table 1 Baseline patient characteristics and injury details

\begin{tabular}{|l|l|l|l|l|l|l|l|l|l|}
\hline Patient & Age & Sex & Injury level & $\begin{array}{l}\text { Mechanism } \\
\text { of injury }\end{array}$ & $\begin{array}{l}\text { Current } \\
\text { smoker }\end{array}$ & Comorbidities & BMI & Concomitant injuries & $\begin{array}{l}\text { Follow-up } \\
\text { (months) }\end{array}$ \\
\hline 1 & 43 & M & TMA & Crush & Yes & HTN & 28.1 & None & 13 \\
\hline 2 & 53 & M & Mid-leg & Fall & Yes & CAD & 22.9 & None & 32 \\
\hline 3 & 37 & M & Through-knee & MVA & No & None & 25.1 & $\begin{array}{l}\text { Splenic laceration, } \\
\text { jejunal injury, multiple } \\
\text { pelvic fractures }\end{array}$ & 2 \\
\hline 4 & 41 & M & BKA & MCC & No & None & 23.7 & Femur fracture & 38 \\
\hline 5 & 32 & F & Foot & PVA & No & None & 21.4 & None & 111 \\
\hline 6 & 69 & M & Through-knee & PVA & No & None & - & $\begin{array}{l}\text { Bilateral femur } \\
\text { fractures, right AKA }\end{array}$ & 59 \\
\hline 7 & 24 & M & Foot & Crush & No & None & 22 & None & 23 \\
\hline 8 & 51 & M & Foot & Crush & No & None & 25 & None & 25 \\
\hline 9 & 29 & M & Lisfranc & $\begin{array}{l}\text { Industrial } \\
\text { paper } \\
\text { shredder }\end{array}$ & No & None & 27.3 & None & 28 \\
\hline 10 & 68 & F & Foot & Crush & Yes & $\begin{array}{l}\text { Diabetes, } \\
\text { neuropathy }\end{array}$ & 25.3 & None & 54 \\
\hline 11 & 48 & M & TMA & MCC/Crush & No & None & 28.8 & Fibula fracture & 5 \\
\hline 12 & 37 & M & Foot & Crush & Yes & None & 27.1 & None & 2 \\
\hline
\end{tabular}

Abbreviations: AKA, above-knee amputation; BKA, below-knee amputation; CAD, coronary artery disease; HTN, hypertension; MCC, motor cycle crash; MP, metacarpophalangeal; MVA, motor vehicle accident; PVA, pedestrian versus automobile; TMA, transmetatarsal amputation.

-: Data not available.

Table 2 Operative information

\begin{tabular}{|l|l|l|l|l|l|}
\hline Patient & Type of free flap & $\begin{array}{l}\text { Time to free } \\
\text { flap (weeks) }\end{array}$ & Arterial anastomosis & Defect size & $\begin{array}{l}\text { Number of operations } \\
\text { after reconstruction }\end{array}$ \\
\hline 1 & Anterolateral thigh & 109 & Anterior tibial & $5 \times 10 \mathrm{~cm}$ & 1 \\
\hline 2 & Rectus abdominis & 143 & Posterior tibial & $30 \times 10 \mathrm{~cm}$ & 12 \\
\hline 3 & Anterolateral thigh & 6 & Descending geniculate & $9 \times 25 \mathrm{~cm}$ & 0 \\
\hline 4 & Rectus abdominis & 2 & Superomedial geniculate & $20 \times 20 \mathrm{~cm}$ & 4 \\
\hline 5 & Latissimus dorsi & 4 & Anterior tibial & $20 \times 10 \mathrm{~cm}$ & 5 \\
\hline 6 & Rectus abdominis & 1 & Branch of the SFA & $40 \times 15 \mathrm{~cm}$ & 5 \\
\hline 7 & Latissimus dorsi & 62 & Posterior tibial & $20 \times 20 \mathrm{~cm}$ & 3 \\
\hline 8 & Rectus abdominus & 1.5 & Dorsalis pedis & $20 \times 20 \mathrm{~cm}$ & 3 \\
\hline 9 & Rectus abdominus & 4 & Dorsalis pedis & $20 \times 10 \mathrm{~cm}$ & 2 \\
\hline 10 & Anterolateral thigh & 156 & Anterior tibial & $5 \times 10 \mathrm{~cm}$ & 0 \\
\hline 11 & Anterolateral thigh & 5 & Dorsalis pedis & $5 \times 10 \mathrm{~cm}$ & 0 \\
\hline 12 & Anterolateral thigh & 2 & Dorsalis pedis & $20 \times 10 \mathrm{~cm}$ & 0 \\
\hline
\end{tabular}

Abbreviation: SFA, superficial femoral artery.

half of the patients had some degree of chronic pain. Most reported that the pain was neuropathic in nature and were on multimodality therapy managed by pain specialists, which included daily oral narcotic use.

\section{Discussion}

High-energy trauma to the extremities often results in soft tissue loss, complex fractures, and sensory loss. These inju- ries have long-lasting, devastating results and patients may be plagued with chronic infection, pain, and contractures which render the extremity nonfunctional and eventually lead to amputation. In this study, we presented our experience with microvascular free flap reconstruction to preserve lower extremity limb length in the trauma setting. We sought to evaluate how microvascular free tissue transfer to the affected limb impacted outcomes, amputation rates and lengths, and functional status. 


\begin{tabular}{|c|c|c|c|c|c|c|c|c|c|c|c|c|}
\hline 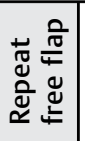 & $\stackrel{0}{z}$ & z & z & z & 2 & z & $\stackrel{\check{\nu}}{\check{\nu}}$ & i & $\stackrel{\tilde{u}}{\succ}$ & in & z & z \\
\hline 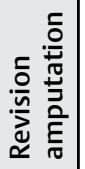 & 2 & $\stackrel{0}{z}$ & $\stackrel{\circ}{z}$ & 20 & 2 & 20 & 20 & 20 & $\stackrel{0}{2}$ & $\frac{0}{2}$ & z & $\frac{5}{2}$ \\
\hline 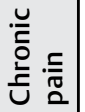 & $\check{y}$ & 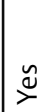 & $\tilde{q}$ & ๘ & 욱 & z & ì & ì & $\stackrel{\check{\nu}}{\nu}$ & ì & z & 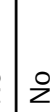 \\
\hline
\end{tabular}

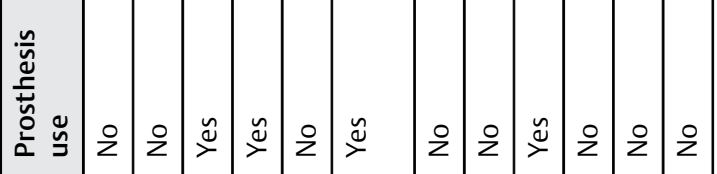

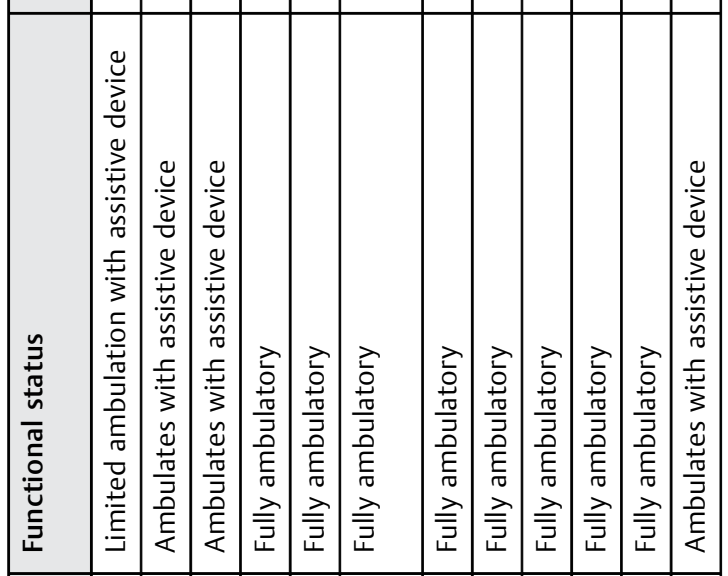

ᄃ

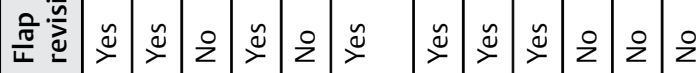

\begin{tabular}{|c|c|c|c|c|c|c|c|c|c|c|}
\hline 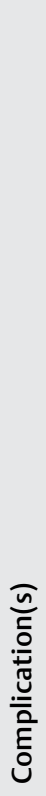 & $\begin{array}{l}0 \\
\text { ò } \\
z\end{array}$ & 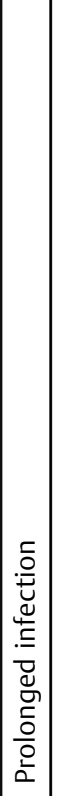 & 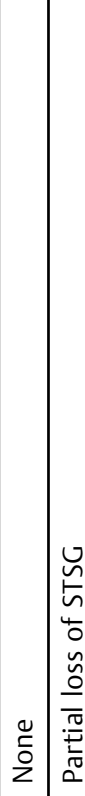 & 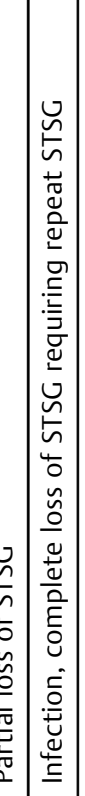 & 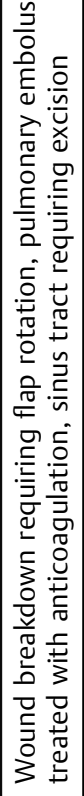 & 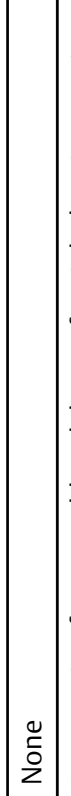 & 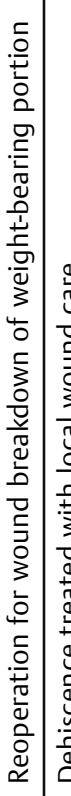 & 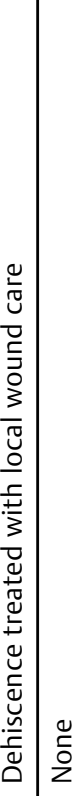 & 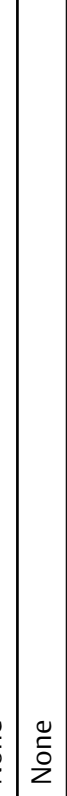 & 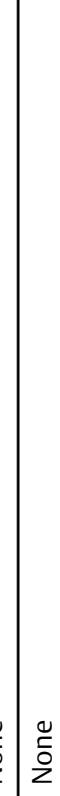 \\
\hline & & & $m \mid r$ & o $\mid$ in & 0 & & & $a 10$ & $=$ & $\simeq$ \\
\hline
\end{tabular}

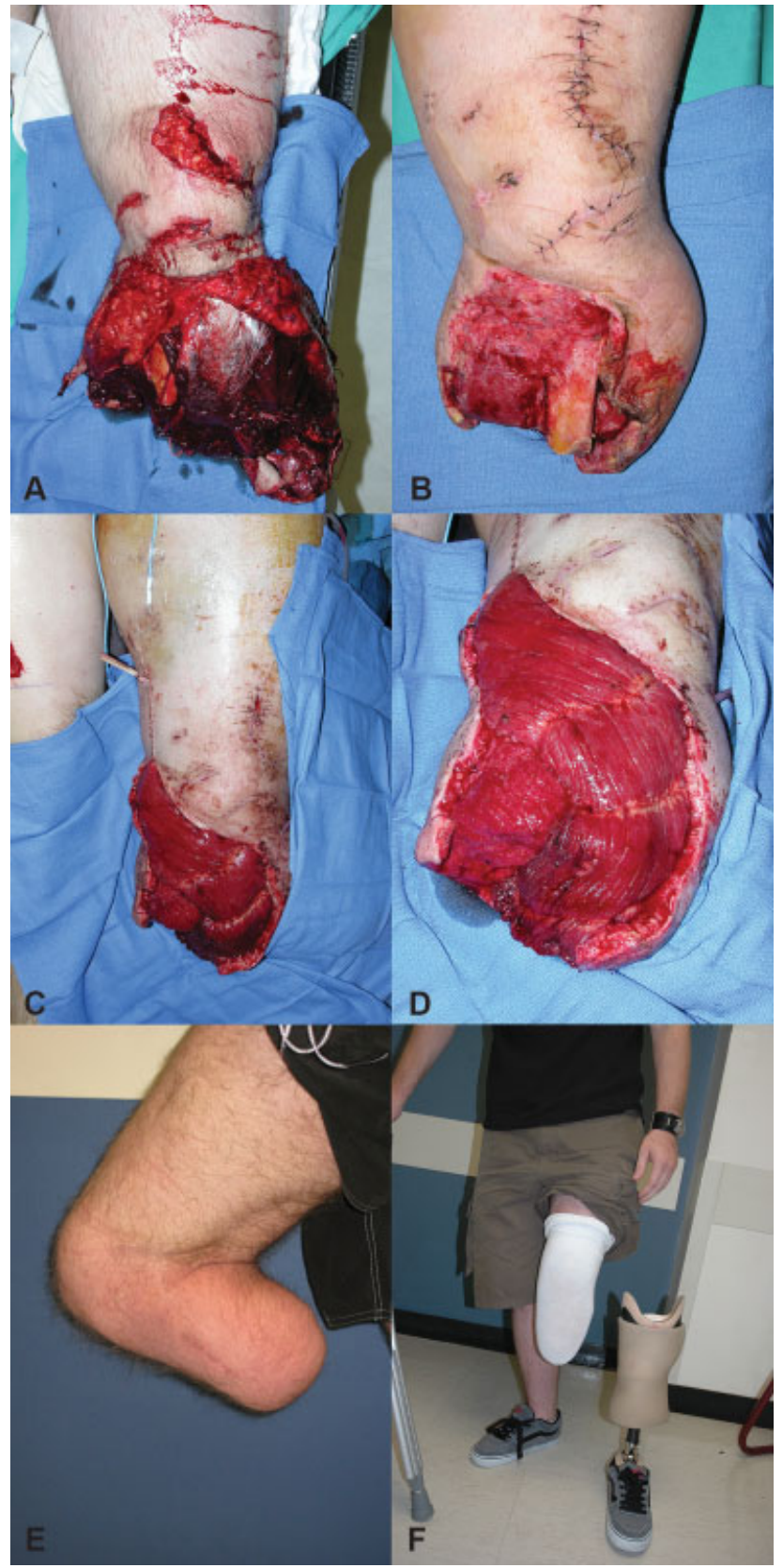

Fig. 1 A 41-year-old police officer sustained a traumatic amputation to his left lower extremity in a motor vehicle accident with soft tissue loss over his anterior tibia. (A) Left leg at initial injury. (B) Leg at the time of free flap reconstruction after serial debridements with orthopedic surgery. (C) A left-sided free rectus abdominis flap was used to reconstruct the soft tissue defect. A saphenous vein graft was used to create an arteriovenous loop to the superior geniculate vessels. (D) The muscle was folded to provide added bulk to the weight-bearing surface. (E) At 5 months postoperatively, the flap was well healed and the patient had excellent knee mobility. (F) The patient is fully ambulatory with the use of a prosthesis.

We presented 12 patients who were treated with microvascular free flap reconstruction to preserve limb length and function following trauma to the extremities. The overall major complication rate was low, and there were no flap losses. Although two patients did require a second free flap, both of these cases were due to chronic pressure on the flap leading to 


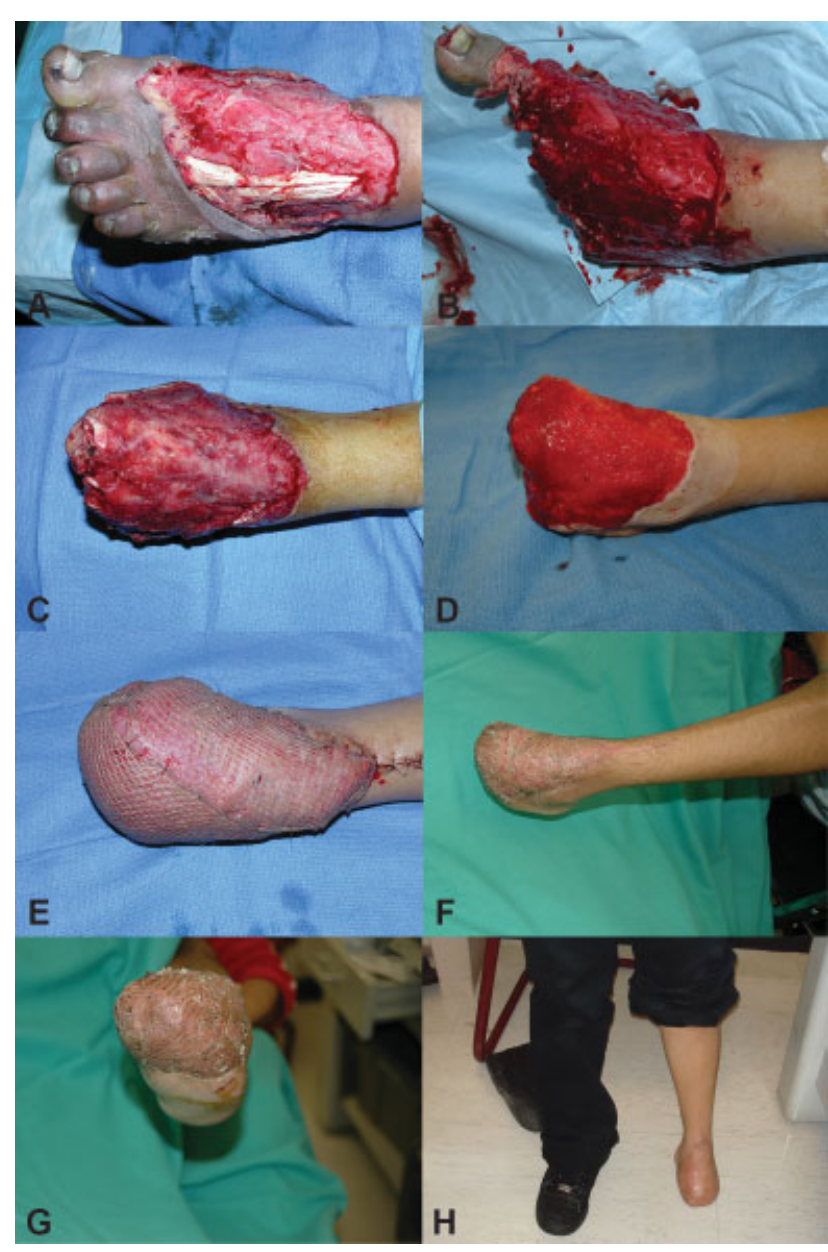

Fig. 2 A 32-year-old woman was run over by a truck sustaining a left open first through fifth metatarsal fracture dislocation with large degloving injury. (A) Initial operative washout and metatarsal pinning. (B) Underwent transmetatarsal amputations of digits two through five 12 days after the initial injury. (C) Underwent transmetatarsal amputation of great toe 14 days after initial injury. (D) Treated with wound vac changes for 1 month to ensure healthy, stable wound bed. (E) Reconstructed with latissimus dorsi muscle flap and split-thickness skin graft anastomosed into the anterior tibial vessels. (F) Had complete loss of skin graft following pseudomonal infection, but repeat skin graft healed without a problem. (G) Weight-bearing surface of the foot well padded. (H) Patient is now fully ambulatory after undergoing two surgeries for correction of equinus deformity.

ulcerations, not due to flap failure. Most patients underwent revisionary surgery to debulk and contour the flap to improve the aesthetic outcome and how the flap fit in a prosthesis or shoe. Interestingly, of the five anterolateral thigh flaps, only one flap required a revision. However, this may have more to do with the shorter follow-up we had with the fasciocutaneous flaps compared with muscle flaps.

The stump length preserved is critical to achieving maximal functionality. Significant improvements in performance and energy expenditure are seen with incremental lengthening of the amputation stump. ${ }^{11}$ In our study, free flap coverage allowed preservation of the foot in nine patients, a BKA instead of a trans-knee amputation in one patient, a through knee amputation instead of a transfemoral amputation in one patient, and maximal AKA length on a bilateral amputee. All patients were able to preserve maximal limb length following traumatic injury.

Overall, we found those patients with lower extremity injuries had better functional outcomes than expected, with the majority fully ambulatory and only one patient who had limited ambulation with an assistive device. However, our patient sample is relatively small and we have no standardized way of reporting functional outcomes because our surgeons do not consistently use a standardized outcome reporting scale, such as the SF-36 or Musculoskeletal Tumor Rating Scale; thus, our conclusions about overall functional outcomes are limited. We are attempting to incorporate these standardized scales into patient care to accurately interpret and assess our outcomes.

While all of our patients were treated with microvascular free tissue transfer for limb salvage or length preservation, it is important to recognize there are several additional reconstructive options available. Trauma patients may benefit from the "spare parts" concept, which involves scavenging tissue for reconstruction that is otherwise unsalvageable and would have been discarded. ${ }^{12-16}$ Applying the concept of using "spare parts," the tibial turn-up plasty and fillet flaps are viable choices for reconstruction. ${ }^{17-20}$ The tibial turn-up plasty repurposes the tibia that would have been amputated as a new surrogate femur to preserve length in femur amputations. ${ }^{18-20}$ Similarly, fillet flaps use tissue from amputated extremities to provide soft tissue bulk in the reconstruction. ${ }^{16,21}$ While these techniques have the benefit of avoiding donor-site morbidity, often the viability of these "spare parts" is severely limited by the amount of healthy tissue available in nonsalvageable segments. ${ }^{12,15,16}$ However, these techniques should be part of a reconstructive surgeon's armamentarium when approaching trauma patients and their devastating injuries.

Unfortunately, trauma patients often have little to no time to process their injuries and evaluate how they will impact their future before deciding whether to pursue limb salvage or primary amputation. Patients who undergo limb salvage instead of primary amputation following trauma face longer hospital courses and more complicated postoperative recoveries. $^{22}$ We found that the majority of our patients required at least one flap revision, and often dealt with chronic pain. Therefore, it is critical that patients and their loved ones understand what limb salvage surgery and the recovery entails, as physical therapy and nonclinical interventions are paramount to successful outcomes. ${ }^{22}$ In these instances, microvascular free tissue transfer can be used to effectively maintain stump length and preserve a functional extremity that would otherwise require amputation.

\section{Conclusion}

Microvascular free tissue transfer can be used to effectively maintain lower extremity stump length following trauma. Although these patients often require multiple surgeries and face lengthy hospital courses, this technique enables preservation of a functional extremity that would otherwise require a more proximal amputation. 


\section{Conflict of Interest}

Dr. Sbitany is on the speaker's bureau for LifeCell, Inc. Drs. Hansen and Lee are consultants for Smith \& Nephew. The remaining authors have no conflicts of interest to disclose.

\section{References}

1 Lister G. Microsurgical transfer of the second toe for congenital deficiency of the thumb. Plast Reconstr Surg 1988;82(04): 658-665

2 Erdmann D, Sundin BM, Yasui K, Wong MS, Levin LS. Microsurgical free flap transfer to amputation sites: indications and results. Ann Plast Surg 2002;48(02):167-172

3 Hallock GG. Evidence-based medicine: lower extremity acute trauma. Plast Reconstr Surg 2013;132(06):1733-1741

4 Georgiadis GM, Behrens FF, Joyce MJ, Earle AS, Simmons AL. Open tibial fractures with severe soft-tissue loss. Limb salvage compared with below-the-knee amputation. J Bone Joint Surg Am 1993;75(10):1431-1441

5 Hansen ST Jr. The type-IIIC tibial fracture. Salvage or amputation. J Bone Joint Surg Am 1987;69(06):799-800

6 Doukas WC, Hayda RA, Frisch HM, et al. The Military Extremity Trauma Amputation/Limb Salvage (METALS) study: outcomes of amputation versus limb salvage following major lower-extremity trauma. J Bone Joint Surg Am 2013;95(02):138-145

7 Gonzalez EG, Corcoran PJ, Reyes RL. Energy expenditure in belowknee amputees: correlation with stump length. Arch Phys Med Rehabil 1974;55(03):111-119

8 Penn-Barwell JG. Outcomes in lower limb amputation following trauma: a systematic review and meta-analysis. Injury 2011;42 (12):1474-1479

9 Tukiainen EJ, Saray A, Kuokkanen HOM, Asko-Seljavaara SL. Salvage of major amputation stumps of the lower extremity with latissimus dorsi free flaps. Scand J Plast Reconstr Surg Hand Surg 2002;36(02):85-90

10 McCarthy ML, MacKenzie EJ, Edwin D, Bosse MJ, Castillo RC, Starr A; LEAP study group. Psychological distress associated with severe lower-limb injury. J Bone Joint Surg Am 2003;85-A(09): 1689-1697

11 Waters RL, Perry J, Antonelli D, Hislop H. Energy cost of walking of amputees: the influence of level of amputation. J Bone Joint Surg Am 1976;58(01):42-46

12 Peng YP, Lahiri A. Spare-part surgery. Semin Plast Surg 2013;27 (04):190-197

13 Lin CH, Webb K, Neumeister MW. Immediate tissue transplantation in upper limb trauma: spare parts reconstruction. Clin Plast Surg 2014;41(03):397-406

14 Riah Y, Balaguer T, Médard de Chardon V, Chignon-Sicard B, Dannan E, Lebreton E. [The use of the "spare-parts tissue bank" concept in emergency hand surgery]. Chir Main 2010;29(01): 23-31

15 Russell RC, Neumeister MW, Ostric SA, Engineer NJ. Extremity reconstruction using nonreplantable tissue ("spare parts"). Clin Plast Surg 2007;34(02):211-222, viii

16 Küntscher MV, Erdmann D, Homann HH, Steinau HU, Levin SL, Germann G. The concept of fillet flaps: classification, indications, and analysis of their clinical value. Plast Reconstr Surg 2001;108 (04):885-896

17 Aderibigbe K, Fletcher JW, Barta RJ, Hill BW, Cole PA. Staged calcaneus osteocutaneous filet flap for salvage of transtibial amputation. Foot Ankle Int 2014;35(01):71-79

18 Van Nesc CP; VAN NESC. Transplantation of the tibia and fibula to replace the femur following resection: turn-up plasty of the leg. J Bone Joint Surg Am 1964;46:1353-1355

19 Tronzo RG, Janek AM. The "turn-up" plasty: one solution to a complex problem. Orthop Nurs 1995;14(03):41-47

20 Ghali S, Harris PA, Khan U, Pearse M, Nanchahal J. Leg length preservation with pedicled fillet of foot flaps after traumatic amputations. Plast Reconstr Surg 2005;115(02):498-505

21 Machol JA IV, Fang RC, Matloub HS. The free fillet flap after traumatic amputation: a review of literature and case report. Hand (N Y) 2013;8(04):487-490

22 Bosse MJ, MacKenzie EJ, Kellam JF, et al. An analysis of outcomes of reconstruction or amputation after leg-threatening injuries. N EnglJ Med 2002;347(24):1924-1931 